\title{
Monitoreo en la prensa digital veracruzana sobre la contingencia sanitaria COVID-19
}

\section{Monitoring in the veracruzana digital press on the health contingency COVID-19}

\author{
Patricia Andrade del Cid ${ }^{a}-$ Mariangel Pablo Contreras ${ }^{b}$ \\ a Responsable del Observatorio Veracruzano de Medios, \\ Centro de Estudios de Opinión y Análisis, Universidad Veracruzana, \\ Xalapa México. Contacto: paandrade@uv.mx. \\ b Observatorio Veracruzano de Medios, Centro de Estudios de Opinión \\ y Análisis, Universidad Veracruzana, Xalapa México.
}

Contacto:mpablo@uv.mx

Recibido: 11 de septiembre de 2020

Aceptado: 15 de octubre de 2020

RESUMEN: El Observatorio Veracruzano de Medios (ObVio) realizó el Monitoreo de la prensa digital veracruzana de la COVID-19 durante los meses de abril y mayo del 2020 en siete medios digitales locales, con el objetivo de indagar en la re-presentación de la pandemia en los medios locales. Para la construcción de variables y categorías se utilizó la metodología que procede del Análisis de Contenido de la Información.

Palabras clave: COVID-19; monitoreo; prensa digital; Veracruz.

ABSTRACT: The Observatorio Veracruzano de Medios (ObVio) carried out the Monitoring of the Veracruz digital press about COVID-19, during the months of April and May 2020 in seven local digital media. The aim of researching was the pandemic's representation in the local media. The methodology of the Content Analysis was used to the construction of variables and categories

Keywords: COVID-19; Monitoring; Digital Press; Veracruz. 
L a misión del Observatorio Veracruzano de Medios $^{1}(\mathrm{ObVio})$ es generar herramientas para un debate y discusión sobre el contenido y función de los medios de comunicación. Para cumplir con esa misión, se realizó el monitoreo en prensa digital veracruzana sobre el COVID-19 en abril y mayo del año 2020. Los monitoreos realizados por ObVio UV sobre temas y problemas ambientales -que se han llevado a cabo cada año desde el 2012-, sirvieron de punto de partida para la construcción de una guía o ficha de análisis del contenido de la información sobre la pandemia; sin embargo, la particularidad de esta contingencia obligó a la construcción de nuevas categorías de análisis. El seguimiento se llevó a cabo durante 14 días aleatorios de los meses de abril y mayo en cinco portales digitales de periódicos impresos: La Opinión de Poza Rica, Diario de Xalapa, El Dictamen, Notivery Mundo de Orizaba; así como dos nativos digitales: Al Calor Político y Formato Siete.

Los criterios de selección de las noticias consistieron en la búsqueda (mediante un procedimiento particular) de aquellas noticias que incluyeran en sus títulos, o primer cuerpo de la nota, las siguientes palabras filtro: COVID-19, Coronavirus, Virus, Epidemia, Pandemia o Contagio. Lo que resultó en un corpus final de 2116 noticias.

Las preguntas de investigación que orientaron el monitoreo fueron las siguientes:

1. ¿Qué relevancia le otorgan los medios analizados a la contingencia? Para contestar esta pregunta se utilizaron categorías como género periodístico: Nota Informativa, Entrevista; y por ser prensa digital, los recursos multimedia que presentaba la noticia: fotografías, video, infografías, etc.

2. ¿Qué temas fueron los que destacaron durante la contingencia y qué actores fueron los protagonistas de la información? Para dar respuesta a esta pregunta se analizaron temas que trataron las noticias: Económicos (afectaciones, apoyos, etc,), Salud (prevención, situación en hospitales, etc), Seguridad/Inseguridad Pública, Vida en Comunidad, etc. Los actores son los protagonistas, es decir, quiénes aparecen en la noticia: Presidente de la República, Alcalde, Subsecretario de Salud, Académicos, etc.

3. ¿Cuáles fueron los rasgos del discurso del periodista ante la contingencia? Para dar respuesta a la noticia se utilizó la variable: "Espectacularización o Sensacionalismo" con categorías como: Morbosidad, Pánico/Miedo, Bienestar Social, Teoría de la Conspiración, etc.

${ }^{1}$ Consultar en: www.uv.mx/blogs/obvio 
El libro de códigos diseñado para el monitoreo de esta pandemia contiene 15 variables que dan respuesta a esas preguntas de investigación.

\section{Principales hallazgos:}

De las 2116 noticias se presentan los principales hallazgos sobre las temáticas emitidas, los declarantes de las mismas y los rasgos del discurso presentado por el periódico o portal analizado.

En la Tabla 1 se muestran los temas que abordaron los portales digitales. El que obtuvo mayor frecuencia fue "Contingencia sanitaria" (37\%), referido a las fases de casos y de defunciones; en este tema los "declarantes" o protagonistas de la noticia fueron funcionarios de la Secretaría de Salud Federales y Estatales. El segundo tema destacado fue "Repercusiones por la contingencia" (24\%), que incluye las consecuencias que se han originado con impacto en la economía y servicios. El declarante que se observó con mayor presencia abordando este tema fueron los Trabajadores locales. De las 2116 noticias, la participación de los Actores de la farándula, deportistas, cantantes y alcalde, autoridad o funcionarios municipales, destacan con un $11 \%$, cada uno. 
Tabla 1.

Declarantes de la noticia por tema abordado

\begin{tabular}{|c|c|c|c|c|c|c|}
\hline \multicolumn{7}{|c|}{ DECLARANTES DE LA NOTA POR TEMA ABORDADO } \\
\hline \multirow[b]{2}{*}{ Declarante } & \multicolumn{5}{|c|}{ Tema } & \multirow[b]{2}{*}{ Total } \\
\hline & $\begin{array}{l}\text { Contingencia } \\
\text { sanitaria }\end{array}$ & $\begin{array}{l}\text { Acciones de } \\
\text { Prevención }\end{array}$ & $\begin{array}{l}\text { Repercusiones en } \\
\text { otros países }\end{array}$ & $\begin{array}{c}\text { Actividades de } \\
\text { Pasatiem po }\end{array}$ & $\begin{array}{l}\text { Re pe rcusiones por } \\
\text { la contingencia }\end{array}$ & \\
\hline $\begin{array}{l}\text { Funcionarios de la Secretaría de Salud } \\
\text { Federal y Estatal }\end{array}$ & 242 & 44 & 4 & 4 & 26 & 320 \\
\hline $\begin{array}{l}\text { Actores de la farándula, de portistas, } \\
\text { cantantes }\end{array}$ & 32 & 39 & 65 & 68 & 22 & 226 \\
\hline $\begin{array}{l}\text { Alcalde, autoridad of funcionarios } \\
\text { municipales }\end{array}$ & 50 & 114 & 2 & 4 & 53 & 223 \\
\hline Trabajadores locales & 24 & 25 & 3 & 4 & 85 & 141 \\
\hline $\begin{array}{l}\text { Empresarios, empresas nacionales o } \\
\text { extranjeras }\end{array}$ & 21 & 22 & 22 & 6 & 67 & 138 \\
\hline $\begin{array}{l}\text { Trabajadores sector salud nacionales e } \\
\text { internacionales (médicos, } \\
\text { enfermeros) }\end{array}$ & 100 & 11 & 8 & 0 & 8 & 127 \\
\hline Ciudadanos comunes, colonos, vecinos & 37 & 37 & 7 & 14 & 26 & 121 \\
\hline $\begin{array}{l}\text { Mandatarios, autoridades de otros } \\
\text { países }\end{array}$ & 21 & 6 & 79 & 3 & 9 & 118 \\
\hline $\begin{array}{l}\text { Investigadores, académicos, } \\
\text { especialistas }\end{array}$ & 55 & 8 & 10 & 9 & 21 & 103 \\
\hline Presidente de México & 21 & 8 & 0 & 3 & 19 & 51 \\
\hline Gobernador del Estado & 14 & 16 & 0 & 2 & 10 & 42 \\
\hline $\begin{array}{l}\text { Poder Legislativo (Senadores, } \\
\text { diputados) }\end{array}$ & 9 & 6 & 2 & 0 & 10 & 27 \\
\hline Otros & 153 & 93 & 43 & 36 & 154 & 479 \\
\hline Total & 779 & 429 & 245 & 153 & 510 & 2116 \\
\hline
\end{tabular}

Fuente: Elaboración propia.

De acuerdo a los resultados por cada portal o nativo digital (Tabla 2), se obtuvo lo siguiente:

El Notiver fue el portal digital que más notas emitió con un total de 396 noticias, de las cuales 40 fueron declaradas por los Mandatarios, autoridades de otros países.

En El Dictamen, de sus 386 noticias, 33 de ellas se abordaron por los funcionarios de la Secretaría de Salud Federales y Estatales. Esta misma tendencia se observó en el Diario de Xalapa, el tercer portal con un mayor número de noticias analizadas (310). 
Tabla 2.

Principales declarantes por cada portal digital

\begin{tabular}{|c|c|c|c|c|c|}
\hline \multicolumn{6}{|c|}{ PRINCIPAL DECLARANTE POR CADA PORTAL/NATIVO DIGITAL } \\
\hline \multirow{2}{*}{$\begin{array}{l}\text { Portal/Nativo } \\
\text { Digital }\end{array}$} & \multicolumn{2}{|c|}{ Total de noticias } & \multirow{2}{*}{ Declarante } & \multicolumn{2}{|c|}{ Noticias } \\
\hline & No. & $\%$ & & No. & $\%$ \\
\hline \multirow{2}{*}{ Notiver } & \multirow{2}{*}{396} & \multirow{2}{*}{$19 \%$} & $\begin{array}{l}\text { Mandatarios, autoridades de otros } \\
\text { países }\end{array}$ & 44 & $11 \%$ \\
\hline & & & $\begin{array}{l}\text { Funcionarios de la Secretaría de } \\
\text { Salud Federales y Estatales }\end{array}$ & 41 & $10 \%$ \\
\hline \multirow{2}{*}{ El Dictamen } & \multirow{2}{*}{386} & \multirow{2}{*}{$18 \%$} & $\begin{array}{l}\text { Funcionarios de la Secretaría de } \\
\text { Salud Federales y Estatales }\end{array}$ & 33 & $9 \%$ \\
\hline & & & $\begin{array}{l}\text { Actores de la farándula, } \\
\text { deportistas, cantantes }\end{array}$ & 29 & $8 \%$ \\
\hline \multirow{2}{*}{ Diario de Xalapa } & \multirow{2}{*}{310} & \multirow{2}{*}{$15 \%$} & $\begin{array}{l}\text { Funcionarios de la Secretaría de } \\
\text { Salud Federales y Estatales }\end{array}$ & 47 & $15 \%$ \\
\hline & & & $\begin{array}{l}\text { Dependencia o Funcionario del } \\
\text { Gobierno Federal }\end{array}$ & 19 & $6 \%$ \\
\hline $\begin{array}{l}\text { Mundo de } \\
\text { Orizaba }\end{array}$ & 306 & $14 \%$ & $\begin{array}{l}\text { Alcalde, autoridad o funcionario } \\
\text { municipal }\end{array}$ & 50 & $16 \%$ \\
\hline \multirow{2}{*}{$\begin{array}{l}\text { La Opinión de } \\
\text { Poza Rica }\end{array}$} & \multirow{2}{*}{275} & \multirow{2}{*}{$13 \%$} & $\begin{array}{l}\text { Alcalde, autoridad o funcionario } \\
\text { municipal }\end{array}$ & 40 & $15 \%$ \\
\hline & & & $\begin{array}{l}\text { Funcionarios de la Secretaría de } \\
\text { Salud Federales y Estatales }\end{array}$ & 32 & $12 \%$ \\
\hline \multirow[t]{2}{*}{ Al Calor Político } & \multirow[t]{2}{*}{271} & \multirow[t]{2}{*}{$13 \%$} & $\begin{array}{l}\text { Funcionarios de la Secretaría de } \\
\text { Salud Federales y Estatales }\end{array}$ & 52 & $19 \%$ \\
\hline & & & Trabajadores locales & 25 & $9 \%$ \\
\hline Formato Siete & 172 & $8 \%$ & $\begin{array}{l}\text { Funcionarios de la Secretaría de } \\
\text { Salud Federales y Estatales }\end{array}$ & 27 & $16 \%$ \\
\hline TOTAL & 2116 & $100 \%$ & & & \\
\hline
\end{tabular}

Fuente: Elaboración propia

En la siguiente Tabla (3) se presentan los temas de las noticias y los rasgos identificados en sus titulares. En un $20 \%$ del total, los discursos que procuraban el "Bienestar Individual o social", se observó en aquellas Acciones de prevención para la propagación del contagio; mientras que el "Miedo/pánico/morbosidad" se observó en el 10\% de los titulares que se categorizaron como Contingencia Sanitaria. 
Observatorios - Observatorio Veracruzano de Medios

Tabla 3.

Rasgo del discurso de la noticia por el tema abordado

\begin{tabular}{|c|c|c|c|c|c|c|}
\hline \multicolumn{7}{|c|}{ RASGOS DEL DISCURSO POR TEMA ABORDADO } \\
\hline \multirow[b]{2}{*}{ Rasgo del discurso } & \multicolumn{5}{|c|}{ Tema } & \multirow[b]{2}{*}{ Total } \\
\hline & \begin{tabular}{|c|} 
Contingencia \\
sanitaria
\end{tabular} & \begin{tabular}{|c|}
$\begin{array}{c}\text { Acciones } \\
\text { de } \\
\text { Prevención }\end{array}$ \\
\end{tabular} & \begin{tabular}{|c|}
$\begin{array}{c}\text { Repercusiones } \\
\text { en otros } \\
\text { paises }\end{array}$ \\
\end{tabular} & $\begin{array}{c}\text { Actividades de } \\
\text { pasatiempo }\end{array}$ & $\begin{array}{c}\text { Repercusiones } \\
\text { por la } \\
\text { contingencia } \\
\end{array}$ & \\
\hline Bienestar individual y social & 122 & 213 & 24 & 16 & 50 & 425 \\
\hline Miedo/pánico/morbosidad & 119 & 28 & 28 & 3 & 55 & 233 \\
\hline Teorias de conspiración & 8 & 0 & 4 & 1 & 0 & 13 \\
\hline $\begin{array}{l}\text { Narrativas del imaginario para } \\
\text { remediar la enfermedad o } \\
\text { contagio }\end{array}$ & 4 & 1 & 4 & 0 & 1 & 10 \\
\hline No aplica & 526 & 187 & 185 & 133 & 404 & 1435 \\
\hline Total & 779 & 429 & 245 & 153 & 510 & 2116 \\
\hline
\end{tabular}

Fuente: Elaboración propia. 